\title{
Visualization and quantification of the atrioventricular conduction axis in hearts with ventricular septal defect using phase contrast computed tomography
}

Shuichi Yoshitake, MD,${ }^{\mathrm{a}, \mathrm{b}}$ Yukihiro Kaneko, MD, PhD, ${ }^{\mathrm{a}}$ Kiyozo Morita, MD, PhD, ${ }^{\mathrm{c}}$ Masato Hoshino, $\mathrm{PhD},{ }^{\mathrm{d}}$ Yoshihiro Oshima, $\mathrm{MD}, \mathrm{PhD},{ }^{\mathrm{e}}$ Masashi Takahashi, $\mathrm{MD}, \mathrm{PhD},{ }^{\mathrm{f}}$ and Robert $\mathrm{H}$. Anderson, $\mathrm{MD}, \mathrm{PhD},{ }^{\mathrm{g}}$ on behalf of the SPring 8 Cardiovascular Structure Analyzing Research Group*

\section{ABSTRACT}

Objective: To visualize and quantify the atrioventricular conduction axis in the setting of ventricular septal defect using phase contrast computed tomography.

Methods: We used the SPring-8 synchrotron radiation facility in Hyogo prefecture in Japan, processing and reconstructing the data with 3-dimensional software.

Results: We studied 8 hearts obtained from patients known to have had ventricular septal defects, aged from 6 to 150 days, with a median of 24.5 days. None of the individuals, however, had undergone corrective surgery. The penetrating bundle was found at a median of $1.43 \mathrm{~mm}$ from the septal crest, with a range of 0.99 to $1.54 \mathrm{~mm}$. The distance to the nonbranching bundle to the right ventricular endocardium was $1.10 \mathrm{~mm}$, with a range from 0.49 to $2.49 \mathrm{~mm}$, to the origin of the left bundle branch was $2.46 \mathrm{~mm}$, with a range from 1.7 to $3.18 \mathrm{~mm}$, and to the origin of the right bundle branch was $2.34 \mathrm{~mm}$, with a range from 0.50 to $2.59 \mathrm{~mm}$. The median distance from the edge of the caudal limb of the septomarginal trabeculation to the right bundle branch was $1.04 \mathrm{~mm}$, with a range from 0.81 to $1.16 \mathrm{~mm}$.

Conclusions: We were able to show the precise location of the axis, with our findings suggesting that longitudinal sutures placed along the posteroinferior rim should be effective in avoiding iatrogenic injury, but sutures should not be placed in the valley between the limbs of the septomarginal trabeculation. (J Thorac Cardiovasc Surg 2020;160:490-6)

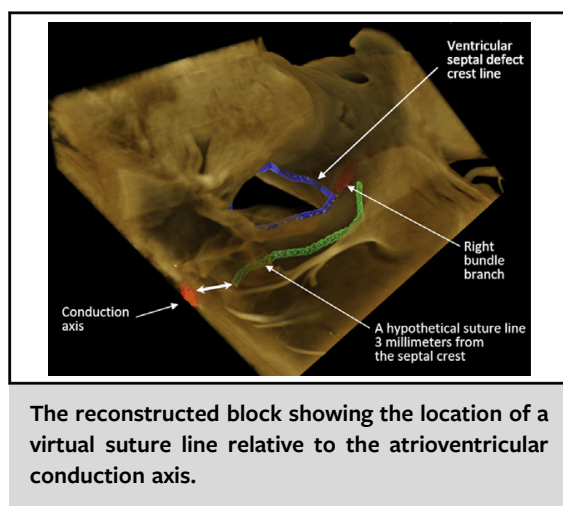

CENTRAL MESSAGE

Use of phase contrast computed tomography revealed the precise location of the atrioventricular conduction axis in the setting of ventricular septal defect, providing information that should help surgeons repair such defects without producing any conduction disturbance.

\section{PERSPECTIVE}

Although now a rare occurrence, iatrogenic heart block remains a risk factor for surgical closure of ventricular septal defects. Our findings validate the previous histologic investigations, permitting the location of the conduc tion axis to be assessed in the setting of 3 -dimensional reconstructions and helping surgeons close such defects without fear of producing any conduction disturbance.

See Commentaries on pages 497,498 , and 500
From the a Division of Cardiovascular Surgery, National Medical Center for Children

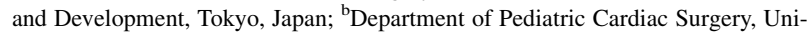
versity of Rochester, Rochester, New York, NY; ${ }^{\mathrm{c} D e p a r t m e n t}$ of Cardiovascular Surgery, Jikei University School of Medicine, Tokyo, Japan; ${ }^{\mathrm{d} J a p a n}$ Synchrotron Radiation Research Institute (SPring-8), Sayo, Hyogo, Japan; ' Department of Cardiovascular Surgery, Kobe Children's Hospital, Kobe, Japan; ${ }^{\mathrm{f}}$ Division of Thoracic and Cardiovascular Surgery, Niigata University Graduate School of Medical and Dental Sciences, Niigata, Japan; and ${ }^{\mathrm{g}}$ Division of Biomedical Sciences, Newcastle University, Newcastle upon Tyne, United Kingdom.

This research is supported by the Practical Research Project for Rare/Intractable Diseases from the Japan Agency for Medical Research and Development, AMED (17ek0109137h0003) and JSPS KAKENHI grant numbers 16K10639, 16K10629, and 18K08771.

\footnotetext{
* Members of SPring 8 Cardiovascular Structure Analyzing Research Group are listed in acknowledgment.

Received for publication Dec 15, 2019; revisions received Feb 9, 2020; accepted for publication Feb 9, 2020; available ahead of print Feb 19, 2020.

Address for reprints: Yukihiro Kaneko, MD, PhD, Division of Cardiovascular Surgery, National Center for Child Health and Development, 2-10-1, Okura, Setagaya, Tokyo 157-8535, Japan (E-mail: kaneko-y@ncchd.go.jp). $0022-5223$

Copyright (C) 2020 The Author(s). Published by Elsevier Inc. on behalf of The American Association for Thoracic Surgery. This is an open access article under the CC BY-NC-ND license (http://creativecommons.org/licenses/by-nc-nd/4.0/). https://doi.org/10.1016/j.jtcvs.2020.02.036
} 
Scanning this QR code will take you to the article title page to access supplementary information.

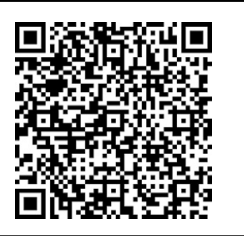

Using histologic analysis, the location of the atrioventricular conduction axis relative to the crest of the ventricular septum was well demonstrated in the 1960s in the setting of ventricular septal defect. ${ }^{1,2}$ These studies showed that, in perimembranous defects, which are the most frequent phenotypic type of defect, the axis penetrates through the fibrous area of valvar continuity that forms the posteroinferior margin of the defects, where it is at greatest risk of iatrogenic damage. ${ }^{3}$ The precise distance of the nonbranching and branching components of the axis from the crest of the deficient septum, however, have still to be determined, although there is evidence that the use of $\mathrm{X}$-ray phase-contrast computed tomography could provide this information. ${ }^{4,5}$ We have, therefore, used this technique to visualize and quantify the precise location of the axis, hopefully providing surgeons with information to close such defects without fear of producing conduction disturbance.

\section{METHODS}

Institutional review board approval was granted October 16, 2015 (number 815 in National Center for Child Health and Development). We obtained 8 hearts from patients who died with ventricular septal defects (Table 1). The ethical committees of the participating hospitals approved our study, waiving the requirement of consent from the family of the deceased. We imaged the hearts using an X-ray Talbot grating interferometer at the beamline BL20B2 in a SPring- 8 synchrotron radiation facility in Hyogo prefecture in Japan. The details of the system, which are markedly different from standard clinical computed tomography, have been described in detail elsewhere. ${ }^{4}$ The image processing and analysis have also been described in detail elsewhere. ${ }^{5}$ The data obtained were processed and reconstructed using version 6.3.0.0 of Amira, along with the Microscopy Image Browser (http:// mib.helsinki.fi/index.html) ${ }^{6}$ and Drishti (https://github.com/nci/ drishti). ${ }^{7}$ In brief, reconstructed volumes were converted to 16-bit tagged image file format slices. The slices were then reconstructed to show the boundaries of the septal defects (Figure 1). When segmenting the axis itself, we distinguished between the penetrating bundle, its nonbranching component, and the right and left bundle branches (Figure 2). We also segmented the septomarginal trabeculation, known as the septal band (Figure 3$)^{8}$

\section{RESULTS}

We were able to identify the conduction axis in 7 of the 8 specimens, all having perimembranous defects opening to the outlet of the right ventricle between the limbs of the septomarginal trabeculation (Figure 3). In all the specimens, the atrioventricular node was located at the apex of the triangle of Koch. The axis then penetrated through the area of fibrous continuity between the leaflets of the mitral, tricuspid, and aortic valves that formed the posteroinferior border of the defect. A relatively long nonbranching component was then found descending down the caudal margin of the defect, before the origin of the left bundle branch, which cascaded down the left ventricular aspect of the septum (Figure 3, upper right-hand panel). The conduction axis then continued as the right bundle branch, which extended along the inferior border of the defect before turning down into the right ventricle beneath the

TABLE 1. Demographics of the specimens

\begin{tabular}{|c|c|c|c|c|c|c|c|}
\hline $\begin{array}{l}\text { Specimen } \\
\text { no. }\end{array}$ & BW, kg & $\begin{array}{l}\text { Year of } \\
\text { autopsy }\end{array}$ & Age, $d$ & Sex & VSD type & Other cardiac anomalies & Other anomalies \\
\hline 1 & 2.65 & 1972 & 6 & M & pm out & ASD, PDA, PLSVC & Anal atresia, TEF, s/p gastrostomy and colostomy \\
\hline 2 & 2.95 & 1979 & 30 & M & $\begin{array}{l}\text { pm out } \\
\quad \text { (malaligned) }\end{array}$ & PDA & $\begin{array}{l}\text { s/p pulmonary artery banding, bilateral inguinal } \\
\text { hernia }\end{array}$ \\
\hline 3 & 1.4 & 1975 & 6 & $\mathrm{~F}$ & pm out & ASD, PDA, PLSVC & $4 \mathrm{p}$ del syndrome, meconium aspiration syndrome \\
\hline 4 & 2.63 & 1980 & 19 & $\mathrm{~F}$ & $\mathrm{pm}$ out & ASD, PDA, PLSVC & \\
\hline 5 & 3.75 & 1977 & 150 & M & $\mathrm{pm}$ & PDA & $\mathrm{s} / \mathrm{p}$ diaphragmatic hernia repair, hypospadias \\
\hline 6 & 3.36 & 1979 & 66 & M & pm out & ASD, CoA, PDA, PLSVC & $\begin{array}{l}18 \text { trisomy, multiple anomalies, Meckel's } \\
\text { diverticulum, malrotation of the mesenteries, } \\
\text { ectopic pancreas, etc }\end{array}$ \\
\hline 7 & 1.02 & 1979 & 8 & $\mathrm{~F}$ & pm out & AS, PDA, ASD, PFO & $\begin{array}{l}18 \text { trisomy, TEF, Meckel's diverticulum, } \\
\text { malrotation of the mesenteries, horseshoe } \\
\text { kidney, multiple anomalies }\end{array}$ \\
\hline 8 & 3.3 & 1983 & 30 & M & pm out & ASD, PDA, MS & \\
\hline
\end{tabular}

$B W$, Body weight; $V S D$, ventricular septal defect; $M$, male; $p m$, perimembraneous; $A S D$, atrial septal defect; $P D A$, patent ductus arteriosus; $P L S V C$, persistent left superior vena cava; TEF, tracheoesophageal fistulae; $s / p$, postoperative status; $F$, female; $C o A$, coarctation of the aorta; $A S$, aortic stenosis; $P F O$, patent foramen ovale; $M S$, mitral stenosis. 


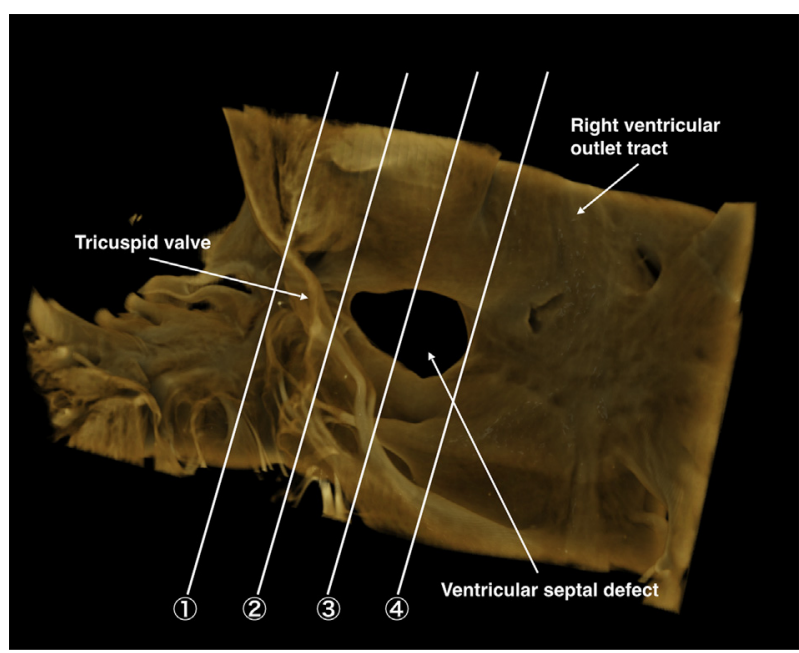

FIGURE 1. The reconstructed block removed from the heart using Drishti software. Each number corresponds to the numbers in Figure 2.

medial papillary muscle (Figure 3, upper left-hand panel). The Amira reconstruction then made it possible for use to reorient the dataset to provide the view as seen by the surgeon working in the operating room (Figure 3, lower left-hand panel). The dataset could also be turned to view the crest of the septum as seen from its cranial aspect. As expected, the ventricular components of the conduction axis occupied the crest of the muscular ventricular septum (Figure 3, lower right-hand panel; Figure 4, specimen \#1).

When assessing all 7 hearts in which it had been possible to discriminate the conduction axis (Figure 3), we found variation in the location of all its components. The median distance of its penetration from the right-sided endocardial surface of the area of fibrous continuity was $1.10 \mathrm{~mm}$, with an interquartile range from 0.49 to $2.49 \mathrm{~mm}$. The greatest degree of left-sided deviation was found at the level of origin of the left bundle branch. This was measured at a median of $1.43 \mathrm{~mm}$ to the left of the septal crest, with an interquartile range from 0.99 to $1.54 \mathrm{~mm}$. As measured from the endocardium on the right ventricular surface of the septum, the median value was $2.46 \mathrm{~mm}$, with an interquartile range from 1.7 to $2.49 \mathrm{~mm}$. At the origin of the right bundle branch, the axis was $2.34 \mathrm{~mm}$ from the right ventricular endocardial surface, with an interquartile range from 0.5 to $2.59 \mathrm{~mm}$ (Figure 3).

Having taken origin from the axis, the right bundle branch coursed through the valley formed between the limbs of the septomarginal trabeculation (Figure 5). Relative to the edge of the caudal limb of the septal band, the median distance was $1.04 \mathrm{~mm}$, with an interquartile range from 0.81 to $1.16 \mathrm{~mm}$.

We were able to make our datasets transparent so as to visualize the overall axis relative to the borders of the defect and the crest of the deficient ventricular septum (Figure 6, right-hand panel). In terms of potential risk of overall damage, this showed the most vulnerable part of the axis to be the point of penetration through the area of fibrous continuity between the mitral and tricuspid valves. We were also able to insert a hypothetical line for suturing placed $3 \mathrm{~mm}$ from the septal crest. Sutures place along this line would not have traumatized the axis (Figure 6, left-hand panel). With regard to the atrial component of the axis, the
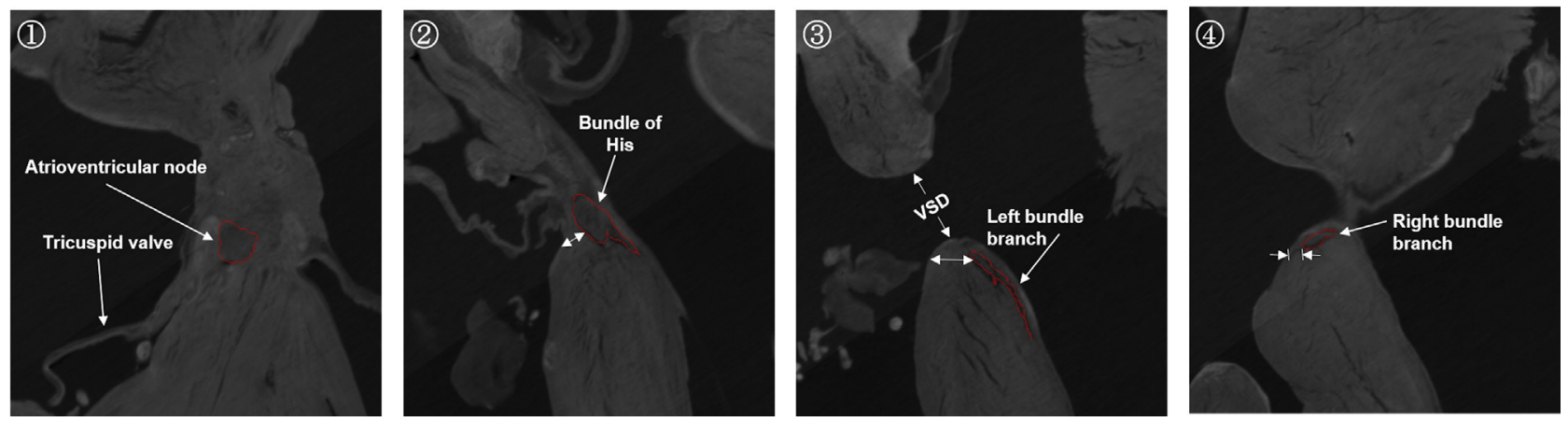

FIGURE 2. Cross-sectional images yielded by phase contrast computed tomography showing the segmentation of the conduction axis colored with a red outline. Measurements in these images showed that the median distance from the right-sided endocardial surface of the area of penetration through the area of fibrous continuity between the leaflets of the mitral and tricuspid valves was $1.10 \mathrm{~mm}$, with an interquartile range from 0.49 to $2.49 \mathrm{~mm}$, as shown by the white double-headed arrow in the second panel. As measured from the endocardium on the right ventricular surface of the septum at the level of origin of the left bundle branch, the median value was $2.46 \mathrm{~mm}$, with an interquartile range from 1.7 to $2.49 \mathrm{~mm}$, as shown by the white horizontal double-headed arrow in the VSD crest in the third panel. With regard to the situation at the origin of the right bundle branch, the axis at this point was $2.34 \mathrm{~mm}$ from the right ventricular endocardial surface, with an interquartile range from 0.5 to $2.59 \mathrm{~mm}$. This is shown by the distance between the 2 white arrows in the fourth panel. $V S D$, Ventricular septal defect. 

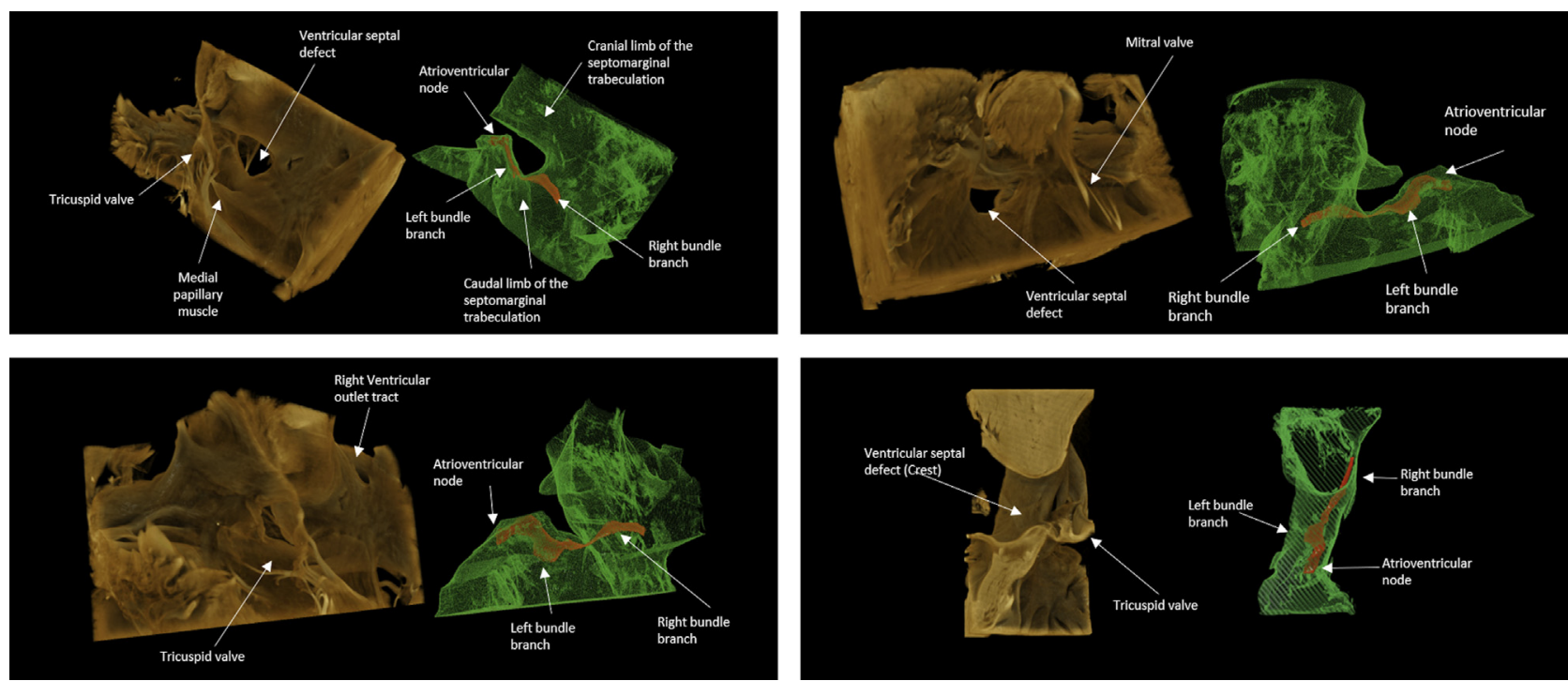

FIGURE 3. The images show the reconstructed block and the segmented regions as viewed from the right ventricular side (upper left-hand panel), the left ventricular side (upper right-hand panel), by the surgeon in the operating room (lower left-hand panel), and from above (lower right-hand panel). The axis has been colored red and the right bundle branch green.
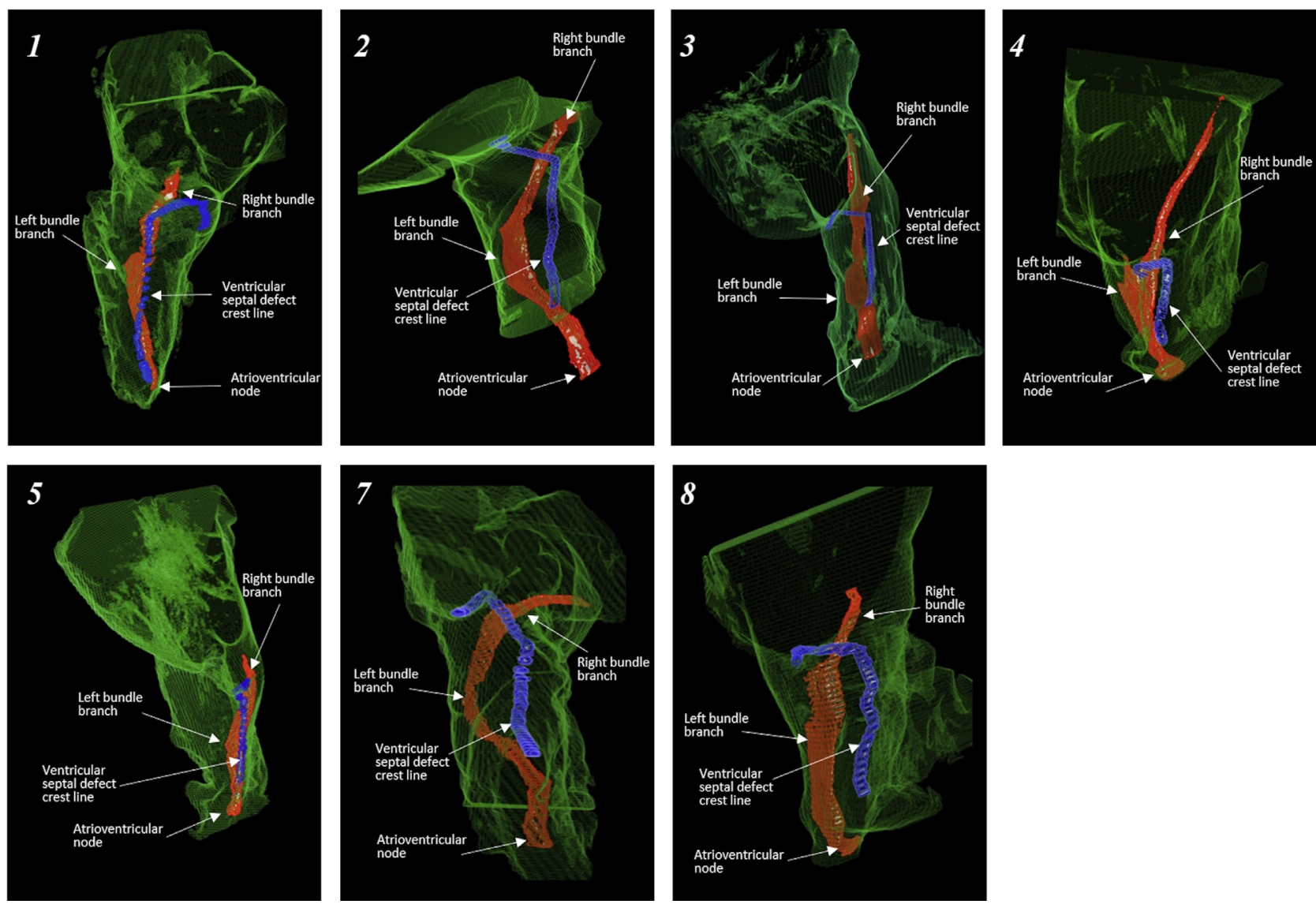

FIGURE 4. The images show the reconstructed blocks from each specimen viewed from above to show the relationship between the conduction axis, shown in red, and the crest of the ventricular septum, shown by the blue line. The greatest degree of left-sided deviation is at the level of origin of the left bundle branch. Relative to the crest of the ventricular septum, this was measured at a median of $1.43 \mathrm{~mm}$, with a range from 0.99 to $1.54 \mathrm{~mm}$. Each number represents the number of the specimen. 

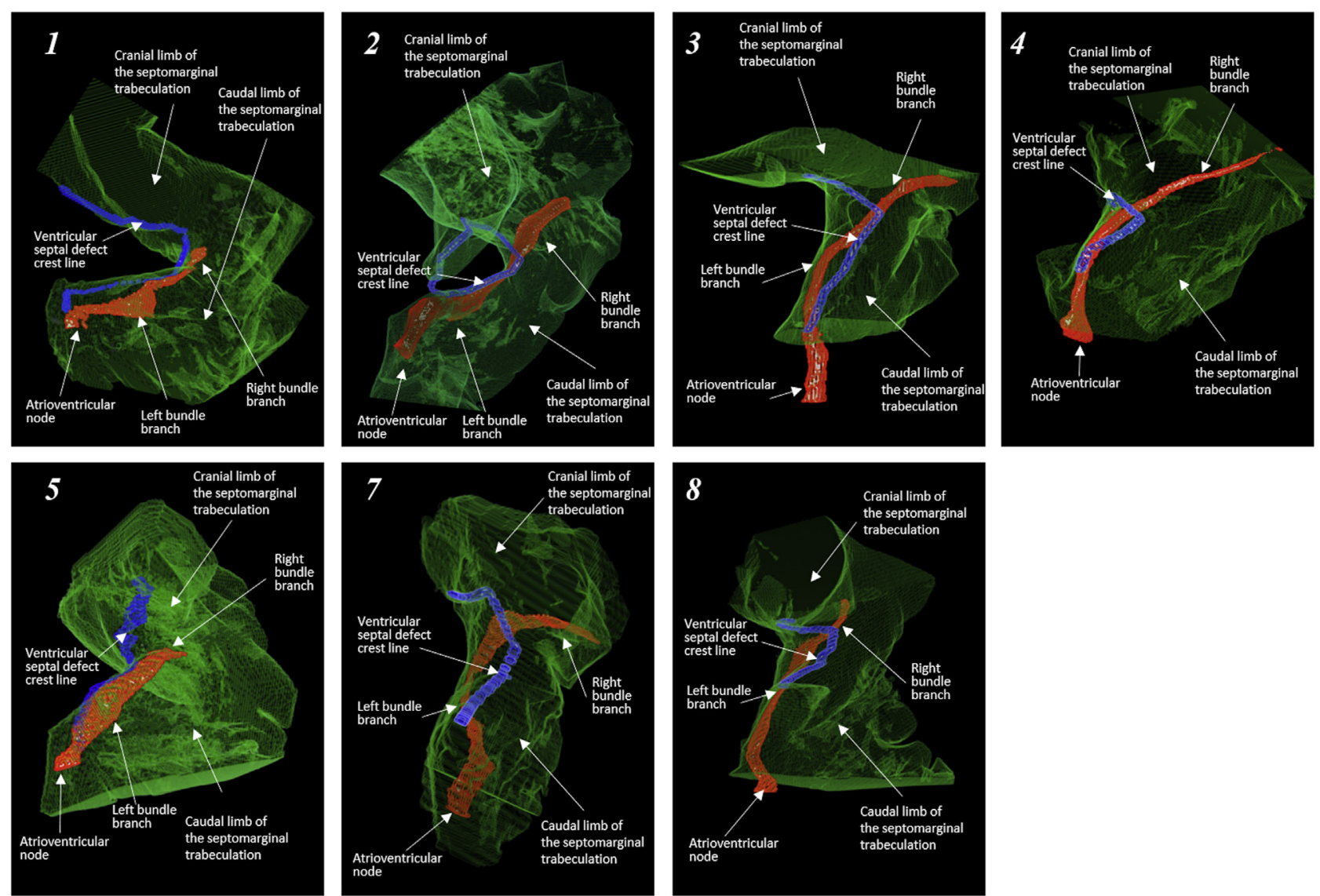

FIGURE 5. The images show the reconstructed blocks as viewed from the right side to show the relationship between the right bundle branch and the valley between the limbs of the septomarginal trabeculation. When measured relative to the edge of the caudal limb of the septal band, the median distance was $1.04 \mathrm{~mm}$, with an interquartile range from 0.81 to $1.16 \mathrm{~mm}$. Each number represents the number of the specimen.

distance between the site of the atrioventricular node and the hinge of the septal leaflet of the tricuspid valve was $3.1 \mathrm{~mm}$ (Video 1).

\section{DISCUSSION}

Although now a rare occurrence, iatrogenic heart block remains a risk factor for surgical closure of ventricular
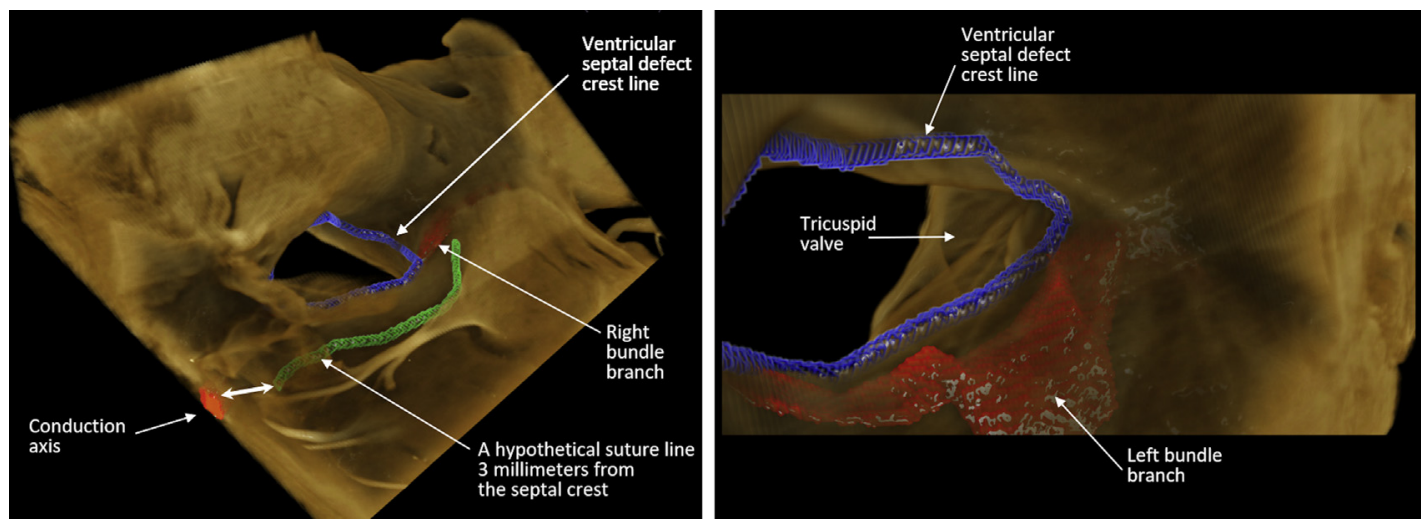

FIGURE 6. Using the Drishti software, we were able to simulate surgical closure of the defect. The right-hand panel shows the area of fibrous continuity between the mitral and tricuspid valves as seen in the operating room, and the left-hand panel shows the view from the left ventricle. We placed a hypothetical suture line $3 \mathrm{~mm}$ from the septal crest. As can be seen, sutures placed along this line would not have traumatized the axis. The white double-headed arrow shows the distance between the site of the atrioventricular node and the hinge of the septal leaflet of the tricuspid valve. This was measured at $3.1 \mathrm{~mm}$ (Video 1 ). 


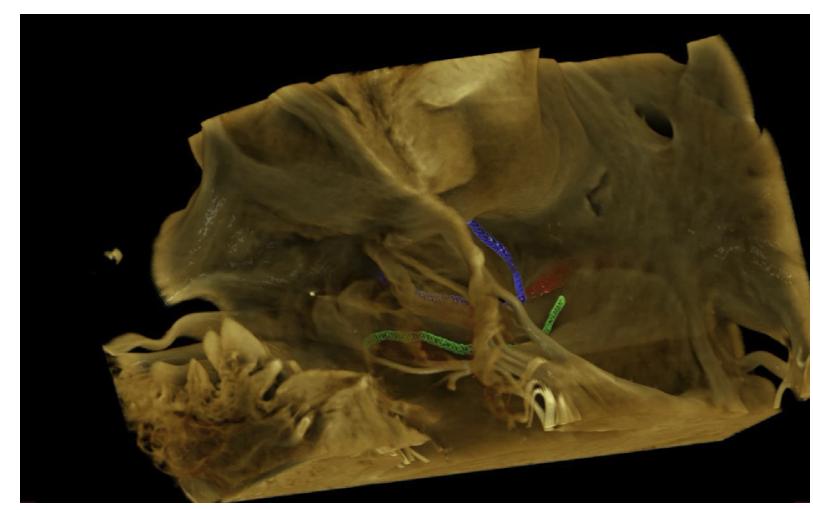

VIDEO 1. The video shows the reconstructed block created by 3-dimensional software simulating surgical closure of the defect. We are able to know the relationship between the hypothetical suture line and the conduction axis. Video available at: https://www.jtcvs.org/article/S0022-5223(20) 30436-0/fulltext.

septal defects. ${ }^{9}$ The safe distance for suturing relative to the ventricular septal crest will, of course, depend on the size of the patient. It is currently recommended by some that stitches should be placed from 5 to $7 \mathrm{~mm}$ below the rim of the septum until the suture line reaches the medial papillary muscle. ${ }^{10}$ Our reconstructions validate these proposals. An alternative recommended technique is to use interrupted pledgeted mattress sutures placed through the septal leaflet of the tricuspid valve in the area of the posteroinferior margin of the defect, continuing to use such pledgeted sutures along its inferior margin. ${ }^{11}$ Despite these recommendations, right bundle branch block continues to be a potential problem when using a right atrial approach. If it occurs, then such disturbances of conduction can be associated with right ventricular dysfunction. ${ }^{12,13}$ Modifications have now been proposed to prevent this complication. ${ }^{14,15}$

We have now shown that the axis is deviated furthest from the crest of the ventricular septum at the level of origin of the take-off of the left bundle branch. It is this component of the axis, from its point of penetration, that is most vulnerable to damage during surgical repair. All our specimens were from infants with a body weight of less than $4 \mathrm{~kg}$. In this setting, our measurements indicate that a longitudinal suture line placed at least $3 \mathrm{~mm}$ from the right endocardial surface should ensure that trauma is avoided during repair. All our specimens, furthermore, had perimembranous defects opening to the outlet of the right ventricle. In all, the right bundle branch took its origin from the axis exactly at the valley formed between the limbs of the septomarginal trabeculation. It follows, therefore, that care should be taken to ensure that sutures are not placed at this key point.
We recognize that our studies using phase-contrast computed tomography do no more than validate the previous histologic examinations. ${ }^{2,16}$ The advantage of our technique is that the reconstructed dataset can be manipulated so as to show views from various aspects, including the view obtained by the surgeon working in the operating room. At the moment, we have studied only hearts with perimembranous defects opening to the right ventricular outlet. The differences in the location of the conduction axis in this setting are relatively minimal. It will now be important to provide comparable datasets for perimembranous defects opening centrally, or to the right ventricular inlet, as well as studying lesions such as tetralogy of Fallot, transposition, or double outlet right ventricle. It will be even more important to conduct similar studies in lesions such as congenitally corrected transposition, where uncertainty still remains regarding the location of the conduction axis when this segmental combination is found in the setting of mirror-imaged atrial arrangement. The technique should also permit assessment of the influence of ventricular topology in the setting of isomerism of the atrial appendages. ${ }^{17,18}$ In this way, we hope to assemble a library of specimens showing the location of the conduction axis in the congenitally malformed heart. Such a library would be a significant educational tool for all those involved with the diagnosis and treatment of those born with these lesions.

We recognize that the technique we used has its limitations. All the specimens we examined had been fixed with formaldehyde, which could have produced differences in terms of the measurements made when compared with living hearts. If the resolution of computed tomography continues to improve, then ideally it should be possible to visualize the conduction axis in the living heart. This, of course, would be the ideal situation. We should also emphasize that phase contrast computed tomography is a research tool and is not available for use in the clinical setting. It remains to be seen whether, with advances in the resolution of machines used for clinical purposes, it will prove possible to demonstrate the location of the conduction axis as a preoperative investigation.

\section{Conflict of Interest Statement}

Authors have nothing to disclose with regard to commercial support.

The SPring 8 Cardiovascular Structure Analyzing Research Group includes Shuichi Yoshitake, MD, Yukihiro Kaneko, MD, $\mathrm{PhD}$, Hiroyuki Morishita, MD, Gen Shinohara, MD, PhD, Kiyozo Morita, MD, PhD, Masato Hoshino, PhD, Ryuma Iwaki, MD, Hironori Matsuhisa, MD, PhD, Yoshihiro Oshima, MD, PhD, Mitsugi Nagashima, MD, PhD, Masashi Takahashi, MD, PhD, and Takuro Tsukube MD, PhD. 


\section{References}

1. Titus JL, Daugherty GW, Edwards JE. Anatomy of the atrioventricular conduction system in ventricular septal defect. Circulation. 1963;28:72-81.

2. Feldt RH, DuShane JW, Titus JL. The anatomy of the atrioventricular conduction system in ventricular septal defect and tetralogy of Fallot: correlations with electrocardiogram and vectorcardiogram. Circulation. 1966; 34:774-82.

3. Hosseinpour AR, Jones TJ, Barron DJ, Brawn WJ, Anderson RH. An appreciation of the structural variability in the components of the ventricular outlets in congenitally malformed hearts. Eur J Cardiothorac Surg. 2007;31: 888-93.

4. Kaneko Y, Shinohara G, Hoshino M, Morishita H, Morita K, Oshima Y, et al. Intact imaging of human heart structure using X-ray phase-contrast tomography. Pediatr Cardiol. 2017;38:390-3.

5. Shinohara G, Morita K, Hoshino M, Ko Y, Tsukube T, Kaneko Y, et al. Three dimensional visualization of human cardiac conduction tissue in whole heart specimens by high-resolution phase-contrast CT imaging using synchrotron radiation. World J Pediatr Congenit Heart Surg. 2016;7:700-5.

6. Belevich I, Joensuu M, Kumar D, Vihinen H, Jokitalo E. Microscopy image browser: a platform for segmentation and analysis of multidimensional datasets. PLoS Biol. 2016;14:e1002340.

7. Limaye A. Drishti: a volume exploration and presentation tool. Proc. SPIE 8506, Developments in X-Ray Tomography VIII, 85060X (17 October 2012).

8. Restivo A, Smith A, Wilkinson JL, Anderson RH. The medial papillary muscle complex and its related septomarginal trabeculation. A normal anatomical study on human hearts. J Anat. 1989;163:231-42.

9. Andersen HØ, de Leval MR, Tsang VT, Elliott MJ, Anderson RH, Cook AC. Is complete heart block after surgical closure of ventricular septum defects still an issue. Ann Thorac Surg. 2006;82:948-56.

10. Inohara T, Ichihara N, Kohsaka S, Miyata H, Hirata Y, Murakami A, et al. The effect of body weight in infants undergoing ventricular septal defect closure: a report from the nationwide Japanese congenital surgical database. J Thorac Cardiovasc Surg. 2019;157:1132-41.

11. Ventricular septal defect. Kouchoukos NT, Blackstone EH, Hanley FL, Kirklin JK, eds. Ventricular septal defect. In: Kirklin/Barratt-Boyes Cardiac Surgery. 4th ed. Philadelphia: Elsevier; 2013:1274-325.

12. Houyel L, Vaksmann G, Fournier A, Davignon A. Ventricular arrhythmias after correction of ventricular septal defects: importance of surgical approach. J Am Coll Cardiol. 1990;16:1224-8.

13. Karadeniz C, Atalay S, Demir F, Tutar E, Ciftci O, Ucar T, et al. Does surgically induced right bundle branch block really effect ventricular function in children after ventricular septal defect closure? Pediatr Cardiol. 2015;36: 481-8.

14. Fukuda T, Suzuki T, Kashima I, Sato M, Morikawa Y. Shallow stitching close to the rim of the ventricular septal defect eliminates injury to the right bundle branch. Ann Thorac Surg. 2002;74:550-5.

15. Varghese R, Saheed S, Ravi AK, Sherrif EA, Agarwal R, Kothandamet S. The "excluding" suture technique for surgical closure of ventricular septal defects: a retrospective study comparing the standard technique. Ann Pediatr Cardiol. 2016;9:229-35.

16. Milo S, Ho SY, Wilkinson JL, Anderson RH. Surgical anatomy and atrioventricular conduction tissues of hearts with isolated ventricular septal defects. J Thorac Cardiovasc Surg. 1980;79:244255.

17. Hosseinpour AR, McCarthy KP, Griselli M, Sethia B, Ho SY. Congenitally corrected transposition: size of the pulmonary trunk and septal malalignment. Ann Thorac Surg. 2004; 77:2163-6.

18. Smith A, Ho SY, Anderson RH, Connell MG, Arnold R, Wilkinsion JL. The diverse cardiac morphology seen in hearts with isomerism of the atrial appendages with reference to the disposition of the specialized conduction system. Cardiol Young. 2006;16:437-54.

Key Words: heart conduction axis, atrioventricular block, ventricular septal defect, phase contrast computed tomography, synchrotrons 